\title{
Nuestra historia en accesos vasculares
}

\author{
Rosa $M^{\text {a }}$ Royo Ruiz, Sonia Alonso Barahona, Ana Isabel Lerín Urmeneta, Laura Gil Rodríguez, Ana Cobos \\ Rincón, Luis Manuel Sainz García
}

\section{Hospital Fundación de Calahorra. La Rioja}

\section{Introducción:}

La necesidad de un AV para realizar Hemodiálisis es tan antigua como la propia hemodiálisis. EI AV ideal no existe si bien la fístula arteriovenosa interna (FAVI) y en especial la radiocefálica, es la que más se aproxima. Como AV alternativo a la FAVI se utiliza la prótesis arteriovenosa (PTFE) y el catéter central venoso (CVC) es la tercera modalidad de AV.

\section{Objetivos:}

Se ha realizado una revisión de los accesos vasculares de nuestra unidad de Hemodiálisis.

\section{Material y métodos:}

Estudio descriptivo retrospectivo desde 2001 hasta octubre de 2012 de los accesos vasculares de los pacientes tratados con hemodiálisis nuestra unidad de hemodiálisis, a partir de la revisión de la historia clínica informatizada de los pacientes y de los registros de la propia unidad.

\section{Desarrollo:}

Hemos revisado un total de 166 pacientes, el 57\% hombres y el $43 \%$ mujeres, con una media de edad 69 años. El tiempo medio de tratamiento con hemodiálisis es de 36 meses. En estos años, se ha finalizado la hemodiálisis el $66 \%$ por éxitus, el $10 \%$ por trasplante, un $2 \%$ se han transferido a diálisis peritoneal, el $19 \%$ se han traslado a otros centros, al $3 \%$ le ha mejorado la función renal y $0.78 \%$ ha abandonado la técnica. Se han registrado un total de 300 accesos vasculares de los cuales 139 (47\%) han sido catéteres y 161(53\%) han sido fístulas incluyendo FAVI y prótesis. Del total de catéteres, el $63 \%$ han sido catéteres temporales, con una colocación mayoritariamente en vena yugular el $73 \%$ y un $27 \%$ en vena femoral. Los catéteres permanentes se distribuyen en su mayoría en vena yugular ( $86 \%$ ), sólo un $2 \%$ en vena subclavia y otro $2 \%$ en vena cava. Se han registrado un $10 \%$ catéteres permanentes sin especificar. La localización de las fístulas es de un $49 \%$ radio cefálicas, el $31 \%$ húmerocefálicas un $6 \%$ húmero basílicas, el $12 \%$ protésicas y un $2 \%$ húmero humeral. La media anual de pacientes que han iniciado diálisis tanto como tratamiento crónico, agudo o transeúntes es de 11.5. Excluyendo el año 2001, cuando se abrió la unidad, que 23 pacientes ya en tratamiento se trasladaron de otros centros. Los accesos vasculares con los que se inicia hemodiálisis es muy variado según el año. El análisis general es del 55\% de los pacientes han iniciado tratamiento con una fístula arteriovenosa, en su mayoría FAVI autóloga, un $5 \%$ prótesis y un $45 \%$ con catéter venoso central. De los pacientes que inician diálisis con catéter el 64\% lo hacen con catéter temporal. Es la vena yugular la de mayor elección en un $69 \%$ y un $31 \%$ con catéter transitorio en vena femoral.

\section{Conclusiones:}

EI CVC es muy utilizado como acceso vascular en nuestro servicio y continua siendo de elección como primer acceso para iniciar la diálisis. Solo hemos analizado datos generales de los accesos vasculares, lo que nos deja una puerta abierta para continuar 
trabajando y evaluando otros aspectos que nos pueda ayudar a mejorar uno de los objetivos principales de la enfermería de esta unidad de Hemodiálisis: EL ACCESO VASCULAR.

\section{Referencias Bibliográficas}

1. M.Mena Mayayo, E. Cerdan Urruti. Manual general de entrenamiento para Hemodiálisis Diaria Domiciliaria: HDDD.Seden. $1^{a}$ edición 2012: 9-10.

2. M.T. MArtinez de Merlo. Manual de accesos vasculares para Hemodiálisis: Cuidados de Enfermería. Seden. $1^{a}$ edición 2012:13-15 y 53-55.

3. Palanca Sanchéz I (Dir.), Conde Olasagasti J (Coord.Cient.), Elola Somoza J (Dir.), Bernal Sobrino JL (Comit. Redac.), Paniagua Caparrós JL(Comit.
Redac.), Grupo de Expertos. Unidad de depuración extrarrenal: estándares y recomendaciones. Madrid: Ministerio de Sanidad, Política Social e Igualdad; 2011:129-131.

4. P. Jiménez Almonacida, E. Grussb, S. Lorenzoc, Manuel Lasalaa,T. Hernándezd, J. Portolésb, J.A. Ruedaa, A. Tatob, Julián del Cerrod y A. Quintansa. Definición de procesos e indicadores para la gestión de accesos vasculares para hemodiálisis. Cir Esp. 2007;81(5):257-63.

5. R.J. Segura-Iglesias, J.M. Gutiérrez-Julián. Guía de acceso vascular en hemodiálisis. ANGIOLOGÍA 2005; 57 (2): 117-118.

6. Sociedad Española de Nefrología, Sociedad Española de Angiología y Cirugía Vascular, Sociedad Española de Radiología Vascular Intervensionista, Sociedad, Española de Enfermedades Infecciosas y Microbiología Clínica, Sociedad Española de Enfermería Nefrológica. Guías de Acceso Vascular en Hemodiálisis. Noviembre-2004. 